\title{
Consequences of high-sensitivity troponin T testing applied in a primary care population with chest pain compared with a commercially available point-of-care troponin T analysis: an observational prospective study
}

Per O Andersson ${ }^{1}$, Jan-Erik Karlsson ${ }^{2,3}$, Eva Landberg ${ }^{4}$, Karin Festin ${ }^{3}$ and Staffan Nilsson ${ }^{5^{*}}$

\begin{abstract}
Background: There is a demand for a highly sensitive and specific point-of care test to detect acute myocardial infarction (AMI). It is unclear if a high-sensitivity troponin assay will have enough discriminative power to become a decision support in primary care. The aim of this study was to evaluate a high-sensitivity troponin T assay performed in three primary health care centres in southeast Sweden and to compare the outcome with a point-of-care troponin T test.

Methods: This study included 115 patients who consulted their general practitioner for chest pain, dyspnoea on exertion, unexplained weakness and/or fatigue in the last 7 days. Troponin T was analysed by a point-of-care test and a high-sensitivity method together with N-terminal pro-B-type natriuretic peptide (NT-proBNP) and creatinine. All patients were checked for AMI or unstable angina (UA) within 30 days of study enrolment. Univariate and multivariate logistic regression was carried out to examine possible connections between troponin $T \geq 15 \mathrm{ng} / \mathrm{L}$, clinical variables and laboratory findings at baseline. In addition, 21 patients with troponin $T \geq 15 \mathrm{ng} / \mathrm{L}$ and no signs of $\mathrm{AMI}$ or UA were followed up for 2-3 years.
\end{abstract}

Results: Three patients were diagnosed with AMI and three with UA. At the $\geq 15 \mathrm{ng} / \mathrm{L}$ cut-off, the troponin T method had $100 \%$ sensitivity, $75 \%$ specificity for AMI and a positive predictive value of $10 \%$. The troponin T point-of-care test missed one case of AMl and the detection limit was $50 \mathrm{ng} / \mathrm{L}$. Troponin $T \geq 15 \mathrm{ng} / \mathrm{L}$ was correlated to age $\geq 65$ years (odds ratio (OR), 10.9 95\% Cl 2.28-51.8) and NT-proBNP in accordance with heart failure (OR 8.62 95\% Cl 1.61-46.1). Fourteen of the 21 patients, without signs of AMI or UA at baseline, still had increased troponin T at follow-up after 2-3 years.

Conclusions: A high-sensitivity troponin T assay could become useful in primary care as a point-of-care test for patients $<65$ years. For patients older than $65-70$ years, a higher decision limit than $\geq 15 \mathrm{ng} / \mathrm{L}$ should be considered and used in conjunction with clinical parameters and possibly with NT-proBNP.

Keywords: Primary health care, Acute coronary syndrome, Chest pain, Troponin T, Point-of-care testing

\footnotetext{
*Correspondence: staffan.g.nilsson@liu.se

${ }^{5}$ Primary Health Care and Department of Medical and Health Sciences,

Linköping University, Norrköping, Sweden

Full list of author information is available at the end of the article
} 


\section{Background}

Chest pain is a challenge for the general practitioner (GP) and is a symptom found in 1-3\% of primary care patients $[1,2]$. Chest pain can be caused by a wide range of illnesses and most are not of cardiac origin. Chest pain is due to ischaemic heart disease in $10-18 \%$ of cases, acute myocardial infarction (AMI) in 2-4\% of cases, or unstable angina (UA) [3, 4], all of which require immediate attention. Cardiac troponin $\mathrm{T}(\mathrm{cTnT})$ is a biomarker specific for cardiac injury and an increased plasma concentration together with a dynamic course is one of the most important criteria for AMI used in hospital care [5]. Some authors have suggested that measurement of cTnT could also help to assess patients with chest pain in primary care [6-10]. In a previous study, we found that the use of a commercially available point-of-care test (POCT) for cTnT may reduce emergency referrals but at the cost of a number of missed cases of AMI or UA [11]. We found that the sensitivity of the POCT-cTnT test to diagnose an AMI was $67 \%$ and for AMI and UA together, only $29 \%$, using the current detection level of $30 \mathrm{ng} / \mathrm{L}$. This emphasizes the need for a more sensitive POCT troponin assay in primary care. However, there are no POCTs for high-sensitivity troponin $\mathrm{T}$ (hs-cTnT) available. The use of a potential hs-cTnT or cTnI test in primary care has some pitfalls. If the blood sample is drawn too early in the course of an AMI, the troponin value may still be below the decision limit and an AMI or UA may be overlooked. There is also a demand for a method with high specificity to avoid results above the decision level with no AMI. This is particularly important in primary care, because AMI is more often not the cause of chest pain in this population [3, 4]. Poor specificity of hs-cTnT has been an issue in several studies and falsely increased $\mathrm{cTnT}$ is common in older patients with decreased renal function $[5,12]$.

The aim of this study was to evaluate an hs-cTnT assay applied to a primary care population with chest pain and to compare the outcome with POCT-cTnT. Another aim was to investigate the persistence of hs-cTnT above the cut-off limit of $15 \mathrm{ng} / \mathrm{L}$ after $2-3$ years in patients with no evidence of acute coronary syndrome.

\section{Methods}

\section{Study design}

An observational prospective study with follow-up was performed between May 2009 and January 2011 in 3 primary health care ( $\mathrm{PHC}$ ) centres in the county of Östergötland, situated in southeast Sweden. In the study published in 2013 by Nilsson et al. [11], samples from 128 patients with chest pain were investigated by POCTcTnT. However, present study includes samples from 115 of these patients because in 13 cases the blood samples were lost (four due to a broken freezer, nine due to other administrative failures). One of these lost cases was diagnosed as UA.

\section{Data collection}

In all three PHC centres, according to normal routines, all patients were given an appointment with their GP after calling the PHC centre and talking to a nurse; the nurse included all eligible patients according to the following inclusion criteria: chest pain, dyspnoea on exertion, unexplained weakness and/or fatigue commencing or becoming aggravated during the last 7 days; age $\geq 35$ years. Exclusion criteria were as follows: patients with symptoms severely affecting their general condition; probable causes of chest pain other than cardiac, according to a nurse's telephone assessment, e.g. costal fracture or gastroesophageal reflux. In addition to the patients included by the nurses, the GPs were asked to include eligible patients in conjunction with consultations.

Management of the patients was noted by the GPs on the case report form developed for the study. The following variables were used: current smoker; ongoing smoking or stopped less than 1 month ago; diabetes, on a diet or medication; hypertension, on medication currently or previously; hypercholesterolaemia, taking cholesterollowering medication; angina pectoris, effort-related chest pain; previous AMI, previous diagnosis of myocardial infarction, also silent myocardial infarctions with obvious changes found on an electrocardiogram (ECG) or echocardiography; coronary revascularization, previous percutaneous coronary intervention or coronary artery bypass graft operation; stroke and heart failure, previously diagnosed; aortic valve disease, insufficiency or stenosis of more than slight significance. A clinical diagnosis of renal failure was based on a plasma creatinine level of $>200 \mu \mathrm{mol} / \mathrm{L}$ in men and $>160 \mu \mathrm{mol} / \mathrm{L}$ in women. An ECG was registered and interpreted by the GPs in conjunction with their first assessment of each patient in the study.

The end point evaluation method is described elsewhere [11]. The cases of AMI and UA in the study were diagnosed in conjunction with the first visit. They could also be diagnosed within 30 days provided they were assessed as missed cases in primary care [11]. The diagnoses of AMI and UA were based on the current definitions [5].

\section{Follow-up of patients with hs-cTnT levels above $15 \mathrm{ng} / \mathrm{L}$ but without signs of AMI or UA}

Twenty-six patients had hs-cTnT levels above $15 \mathrm{ng} / \mathrm{L}$ but no evidence of AMI or UA within 30 days after drawing the blood sample. Three of the patients had died by the follow-up. The remaining 23 were invited for a follow-up examination. One patient declined due to advanced cancer and one had moved to another county in Sweden. The 
remaining 21 accepted the invitation. The patients were asked to avoid physical exercise the day before the examination because earlier studies have shown that physical exercise or hard physical training can cause increased hscTnT levels [13]. Follow-up was performed at the PHC centre where the patient had chosen to be listed. The time after inclusion in the study varied between 25 and 42 months (average 34 months). In all 21 cases, the follow-up was performed by the same researcher.

All patients were asked the same questions from a special form that was produced exclusively for this study and the same procedure was used for everyone. Data on ECG, weight, height, body mass index, waist circumferences and blood pressure were collected. An ECG was registered and compared with the ECG that was performed at the start of the study. We searched for new findings, i.e. atrial fibrillation, ST elevation and pathologic q-waves. Blood pressure was taken from the right arm with the patient in a sitting position; patients rested for $5 \mathrm{~min}$ before the measurements were taken. Waist circumference was measured with the patient in a standing position during exhalation. Blood samples were collected by venipuncture and sent for analysis of cholesterol, creatinine, $\mathrm{N}$-terminal pro-B-type natriuretic peptide (NT-proBNP) and hs-cTnT on the same day. The diagnosis of heart failure was based on impaired left ventricular function according to echocardiogram if performed earlier, and/ or by clinical findings. Ten of the patients had undergone echocardiogram from 8 years to 6 months before the follow-up. At the consultation, the patients were asked about new symptoms since inclusion in the study, i.e. chest pain, dyspnoea, angina or exercise-related chest pain.

\section{Analytical methods Blood samples}

Blood was collected by venipuncture in vacuum tubes containing separating gel and lithium heparin $(4 \mathrm{~mL}$; Greiner Bio-One, Frickenhausen, Germany) or separating gel and silica coagulation activator $(4 \mathrm{~mL}$; Greiner Bio-One). After resting for 30-60 min, the tubes were centrifuged at $2,400 \times g$ for $5 \mathrm{~min}$. Aliquots of serum and plasma were stored initially at $-20^{\circ} \mathrm{C}$ for less than 1 month, after which the samples were transferred to $-70^{\circ} \mathrm{C}$ and kept frozen until analysis.

\section{POCT-cTnT}

Troponin $\mathrm{T}$ was measured on the POCT instrument Cobas h232 (Roche Diagnostics, Mannheim, Germany). The detection limit was $0.03 \mu \mathrm{g} / \mathrm{L}(30 \mathrm{ng} / \mathrm{L})$ and all values $>0.03 \mu \mathrm{g} / \mathrm{L}$ ( $>30 \mathrm{ng} / \mathrm{L}$ ) were regarded as positive according to the manufacturer's recommendations. Further details about the method for POCT-cTnT are described elsewhere [11].

\section{hs-cTnT}

Cardiac troponin $\mathrm{T}$ was measured in plasma by immunochemical methods using detection based on luminescence on a Cobas e602 instrument (Roche Diagnostics, Mannheim, Germany). The method used for cTnT was a highly sensitive method with a limit of detection of $1 \mathrm{ng} / \mathrm{L}$. A decision limit of $\geq 15 \mathrm{ng} / \mathrm{L}$ was used. This limit was based on the 99th percentile calculated for a healthy population, according to Roche [14]. The lot number of the reagent was 167,650 and of the calibrator 165,095. These are new revised lots. However, when patients were admitted to the hospital, the diagnosis was based on hscTnT values measured by the old non-revised lots, which, according to Roche, have recently been found to produce low results in the interval 3-20 ng/L [15]. The coefficient of variation $(\mathrm{CV})$ for a 2 -month period was $2.9 \%$ (level $24 \mathrm{ng} / \mathrm{L}$ ) and 3.6\% (level 1,600 ng/L) for hs-cTnT.

\section{Other laboratory analyses}

Creatinine was measured in plasma samples from all patients using a standardized method (Advia 1800; Siemens Healthcare Diagnostics, Deerfield, IL, USA). The method was based on Jaffe reagent and contained a rateblanking measurement to compensate for interference from bilirubin and a correction for intercept due to pseudocreatinines. An estimated glomerular filtration rate (eGFR) was calculated based on the creatinine level using the modification of diet in renal disease equation [16].

$\mathrm{N}$-terminal pro B-type natriuretic peptide (NTproBNP) was measured in plasma samples from all patients at baseline and at follow-up. Analysis was performed on a Cobas e602 instrument (Roche Diagnostics). This assay is based on immunochemistry with 2 monoclonal antibodies and electrochemiluminescence detection.

Cholesterol was measured in plasma samples from patients at the follow-up. Analysis was performed on an Advia 1800 instrument (Siemens Healthcare Diagnostics) by a method with reagent and calibrator from the same company. The reference ranges used were $3.3-6.9 \mathrm{mmol} / \mathrm{L}$ (31-50 years) and $3.9-7.8 \mathrm{mmol} / \mathrm{L}$ (>50 years) [17].

\section{Statistical analysis}

At baseline and at the follow-up, possible differences regarding demographics (age, gender), risk factors (smoking habits, diabetes, hypertension and hypercholesterolaemia), cardiovascular disease (angina pectoris, previous AMI, coronary revascularization, stroke, heart failure and aortic valve disease), ECG findings (sinus rhythm, atrial fibrillation), and laboratory findings (renal failure, eGFR, NT-proBNP, and potential causes of increased hs-cTnT) between patients with hs-cTnT levels above or below $15 \mathrm{ng} / \mathrm{L}$ were tested with the Pearson $\chi^{2}$ test and the Fisher exact test if the data were discrete. Continuous data 
were analysed with the Student $t$ test if approximately normally distributed, otherwise the non-parametric Mann-Whitney test was used. Univariate and multivariate logistic regression was carried out to examine possible differences between high and low hs-cTnT levels at baseline regarding all the variables, except renal failure and potential causes of increased hs-cTnT (due to small numbers). In the logistic regression models, the continuous variable NT-proBNP was transformed into a dichotomous variable according to age and a high likelihood of heart failure, i.e. $>450 \mathrm{ng} / \mathrm{L}$ ( $<50$ years), $>900 \mathrm{ng} / \mathrm{L}$ (5075 years) and $>1,800 \mathrm{ng} / \mathrm{L}$ ( $>75$ years) [18].

Age was also transformed into a dichotomous variable; $>65$ years according to the results for emergency room patients reported by Hammarsten et al. [12] and our own findings (Figure 1). Data on angina pectoris, AMI and percutaneous coronary intervention/coronary artery bypass graft were combined into one variable due to small numbers. All variables were adjusted for sex and age in the univariate models, and those who had a $P$ value $<0.10$ were considered for the multivariate model. A $P$ value $<0.05$ was considered statistically significant.

\section{Ethics}

The Regional Ethical Review Board in Linköping, Sweden (Dnr M101-09, T98-09 and Dnr 2010/211-32) approved the study. Written informed consent was obtained from all patients before enrolment in the study.

\section{Results}

One hundred and fifteen patients were enrolled in the study. Only three had AMI and three had UA. Thirty-one patients had hs-cTnT $>15 \mathrm{ng} / \mathrm{L}$. The group with hs-cTnT $>15 \mathrm{ng} / \mathrm{L}$ was on average 15 years older, more often male and more often diagnosed with heart failure or atrial fibrillation. They also had lower eGFR and higher NTproBNP compared with those with hs-cTnT $<15 \mathrm{ng} / \mathrm{L}$ (Table 1). hs-cTnT analysis had a much higher sensitivity

Table 1 Clinical characteristics of 115 patients with chest pain in relation to the level of hs-cTnT

\begin{tabular}{|c|c|c|c|c|}
\hline & $\begin{array}{l}\text { Chest pain patients } \\
n=115\end{array}$ & $\begin{array}{l}\text { hs-cTnT-T }<15 \mathrm{ng} / \mathrm{L} \\
n=84\end{array}$ & $\begin{array}{l}\text { hs-cTnT-T } \geq 15 \mathrm{ng} / \mathrm{L} \\
n=31\end{array}$ & $P$ value \\
\hline \multicolumn{5}{|l|}{ Demographics } \\
\hline Age, years & $65 \pm 14$ & $61 \pm 13$ & $76 \pm 11$ & $<0.001$ \\
\hline Sex, male & $66(57)$ & $41(49)$ & $25(81)$ & 0.003 \\
\hline \multicolumn{5}{|l|}{ Risk factors } \\
\hline Current smokers & $15(13)$ & $12(14)$ & $3(10)$ & 0.756 \\
\hline Diabetes & $17(15)$ & $9(11)$ & $8(26)$ & 0.072 \\
\hline Hypertension & $42(37)$ & $25(30)$ & $17(55)$ & 0.017 \\
\hline Hypercholesterolaemia & $34(30)$ & $22(26)$ & $12(39)$ & 0.250 \\
\hline \multicolumn{5}{|l|}{ Cardiovascular disease } \\
\hline Angina pectoris & $20(17)$ & $11(13)$ & $9(29)$ & 0.056 \\
\hline Previous AMI & $19(17)$ & $12(14)$ & $7(23)$ & 0.395 \\
\hline Coronary revascularization & $14(12)$ & $10(12)$ & $4(13)$ & 1.000 \\
\hline Stroke & $4(3.5)$ & $3(3.6)$ & $1(3.2)$ & 1.000 \\
\hline Heart failure & $11(10)$ & $4(4.8)$ & $7(23)$ & 0.008 \\
\hline Aortic valve disease & $4(3.5)$ & $1(1.2)$ & $3(9.7)$ & 0.059 \\
\hline Renal failure clinically diagnosed & $1(0.9)$ & $0(0)$ & $1(3.2)$ & 0.270 \\
\hline \multicolumn{5}{|l|}{ ECG findings } \\
\hline Atrial fibrillation & $12(10)$ & $3(3.6)$ & $9(29)$ & $<0.001$ \\
\hline \multicolumn{5}{|l|}{ Laboratory findings } \\
\hline POCT-cTnT >30 ng/L & 4 & 0 & 4 & $N A^{a}$ \\
\hline $\mathrm{eGFR}, \mathrm{mL} / \mathrm{min}$ & $68 \pm 16$ & $71 \pm 15$ & $59 \pm 15$ & $<0.001$ \\
\hline NT-proBNPb & $13(11)$ & $2(2.4)$ & $11(37)$ & $<0.001$ \\
\hline \multicolumn{5}{|l|}{ Other } \\
\hline $\begin{array}{l}\text { Potential causes of increased troponin T in the } \\
\text { absence of overt ischaemic heart disease, } n(\%)^{c}\end{array}$ & $1(0.9)$ & $1(1.2)$ & $0(0)$ & 1.000 \\
\hline
\end{tabular}


for finding AMI (100 vs 67\%) and the combination of AMI and UA (83 vs 33\%) compared with POCT-cTnT. However, this increase in sensitivity was at the expense of greatly reduced specificity, from $98 \%$ to $75-76 \%$. The positive predictive value (PPV) was only $10 \%$ for AMI and $16 \%$ for the combination of AMI and UA (Table 2). Besides a diagnosis of AMI or UA (odds ratio (OR) 53.8 95\% CI 3.37-859), the multivariate analysis showed that age at least 65 years (OR 10.9 95\% CI 2.28-51.8) and an NT-proBNP value in accordance with heart failure (OR $8.6295 \%$ CI 1.61-46.1) were significantly related to hscTnT >15 ng/L (Table 3). Atrial fibrillation and eGFR showed a significant association with the level of hs-cTnT in the clinical characteristics (Table 1), as well as in the logistic univariate models (not shown). The significance disappeared after adjusting these variables for age and sex. They were therefore excluded from the final model, although the $P$ values ( 0.073 and 0.079 , respectively) indicated a tendency to association with the level of hs-cTnT. The time between onset of symptoms and examination by the GP and blood sampling was at least $10 \mathrm{~h}$. Figure 1 shows the individual values of hs-cTnT in relation to age. It is also clear that samples with hs-cTnT values between 30 and $50 \mathrm{ng} / \mathrm{L}$ failed to give positive values on the POCT-cTnT instrument (Cobas h232) in contradiction to the manufacturer's specifications (a detection limit of $30 \mathrm{ng} / \mathrm{L})$.

Follow-up of patients with hs-cTnT levels $>15 \mathrm{ng} / \mathrm{L}$ but without signs of AMI or UA

Twenty-four patients with hs-cTnT $\geq 15 \mathrm{ng} / \mathrm{L}$ without any signs of AMI or UA were enrolled in the followup after 2-3 years. Three of these patients had died, all men, at the ages of 86, 89 and 93 years (two died of heart failure and one in cardiac arrest), leaving 16 men and 5 women in the remaining group to be investigated. These 21 patients had no anamnestic or ECG signs of AMI during the follow-up. Eighteen of these patients had a diagnosis of hypertension. However, according to measurements, their blood pressure was well regulated with a mean value of $120 \mathrm{~mm} \mathrm{Hg}$ systolic and $70 \mathrm{~mm} \mathrm{Hg}$ diastolic. All patients had cholesterol values below the reference limit (Table 4). In seven patients, hs-cTnT was normalized but in 14 cases hs-cTnT was still $>15 \mathrm{ng} / \mathrm{L}$ (Table 4). The group with persistent increased hs-cTnT was on average 8 years older, had lower eGFR and higher NT-proBNP compared with the group with normalized hs-cTnT (Table 4). Atrial fibrillation was more common in the group with hs-cTnT $>15 \mathrm{ng} / \mathrm{L}$ although not statistically significant.

Table 2 Diagnostic accuracy of point-of-care test for cardiac troponin T (POCT-cTnT) and high sensitivity cardiac troponin T (hs-cTnT) to find acute myocardial infarction (AMI) and the combination of AMI or unstable angina (UA)

\begin{tabular}{|c|c|c|c|c|c|c|c|c|}
\hline & \multicolumn{2}{|c|}{ Sensitivity } & \multicolumn{2}{|c|}{ Specificity } & \multicolumn{2}{|l|}{ PPV } & \multicolumn{2}{|l|}{ NPV } \\
\hline & $n$ & $\%$ & $n$ & $\%$ & $n$ & $\%$ & $n$ & $\%$ \\
\hline \multicolumn{9}{|l|}{ AMI } \\
\hline POCT-cTnT & $2 / 3$ & 67 & $110 / 112$ & 98 & $2 / 4$ & 50 & $110 / 111$ & 99 \\
\hline hs-cTnT & $3 / 3$ & 100 & $84 / 112$ & 75 & $3 / 31$ & 10 & $84 / 84$ & 100 \\
\hline \multicolumn{9}{|l|}{ AMI/UA } \\
\hline POCT-cTnT & $2 / 6$ & 33 & $107 / 109$ & 98 & $2 / 4$ & 50 & $107 / 111$ & 96 \\
\hline hs-cTnT & $5 / 6$ & 83 & $83 / 109$ & 76 & $5 / 31$ & 16 & $83 / 84$ & 99 \\
\hline
\end{tabular}

Decision limit: POCT-cTnT >30 ng/L, hs-cTnT >15 ng/L.

Table 3 Odds ratios (OR) for 115 patients with chest pain to have hs-cTnT $\geq 15 \mathrm{ng} / \mathrm{L}$ using univariate and multivariate logistic regression

\begin{tabular}{lclclccc}
\hline & Beta & Standard error & Wald & Df & $\boldsymbol{P}$ & OR & 95\% confidence interval \\
\hline Age (65 years or older) & 2.39 & 0.80 & 8.95 & 1 & 0.003 & 10.9 & $2.28-51.8$ \\
Sex (male) & 1.11 & 0.59 & 3.54 & 1 & 0.060 & 3.02 & $0.96-9.56$ \\
NT-proBNPa & 2.15 & 0.86 & 6.33 & 1 & 0.012 & 8.62 & $1.61-46.1$ \\
AMl or UA & 3.99 & 1.41 & 7.94 & 1 & 0.005 & 53.8 & $3.37-859$ \\
Constant & -3.89 & 0.85 & 21.0 & 1 & 0.000 & 0.02 & \\
\hline
\end{tabular}

a $>450 \mathrm{ng} / \mathrm{L}$ ( $<50$ years), $>900 \mathrm{ng} / \mathrm{L}$ ( $50-75$ years), and $>1,800 \mathrm{ng} / \mathrm{L}$ ( $>75$ years). 


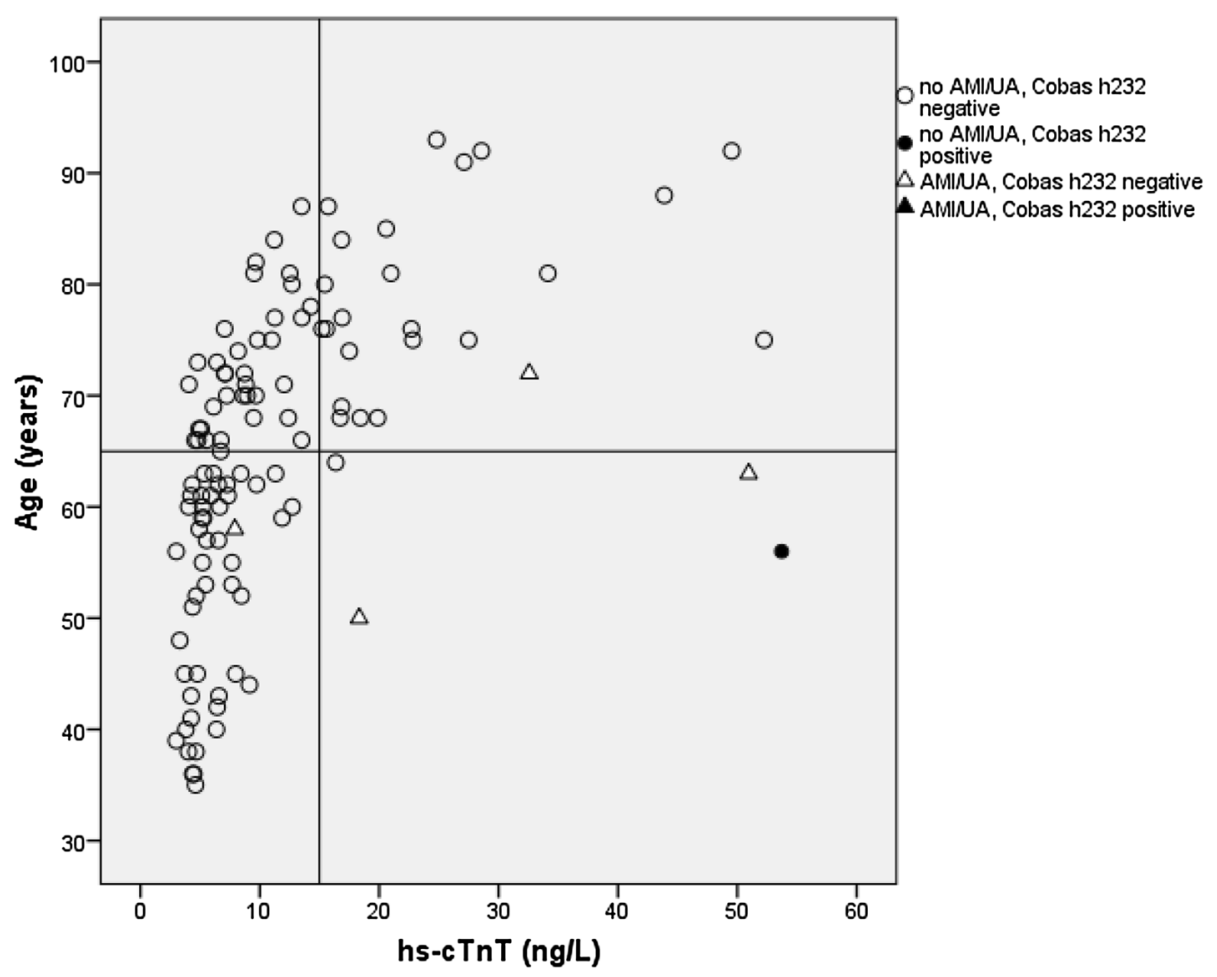

Figure 1 hs-cTnT values for 112 patients with chest pain in relation to age. The results from Cobas h232 were noted as positive in 4 cases (i.e. $>30 \mathrm{ng} / \mathrm{L}$ ). Three of these results are not shown in the figure because their hs-cTnT values were 204, $220 \mathrm{and} 520 \mathrm{ng} / \mathrm{L}$. Two of these patients had AMI.

\section{Discussion}

A considerable number of patients consulting PHC have chest pain and other symptoms suggesting AMI or UA. The challenge to distinguish between heart disease and symptoms in the thoracic area due to other causes are well known amongst GPs.

The sensitivity for hs-cTnT to find AMI or the combination of AMI and UA was 100 and 83\%, respectively, i.e. substantially better than for POCT-cTnT. The specificity of hs-cTnT was lower compared with the POCT method, but was similar to the findings in a population with acute chest pain in the emergency department (ED) (75\%). However, the PPV for AMI in our study was only $10 \%$ compared with $63 \%$ in the ED [19]. This emphasizes the difficulty with interpreting hs-cTnT results in conjunction with outcome. In order to investigate if the diagnostic usability of hs-cTnT could be improved, we performed a multivariate analysis to evaluate other possible explanations for an increased hs-cTnT level. Age 65 years or more was strongly correlated to a troponin $\mathrm{T}$ level $\geq 15 \mathrm{ng} / \mathrm{L}$. This in accordance with the findings of Hammarsten et al. [12] who found highly age-dependent $c \operatorname{TnT}$ percentiles above a breaking point of around 65 years in ED patients without conditions that increase cTnT. In accordance with our results, several authors have suggested that a higher decision limit must be considered for patients older than $65-70$ years [12, 20, 21]. In our study, male sex was at the limit of significance (Table 3). Population-based studies on people of younger ages have shown higher cTnT values for men compared with women [14]. This has also been found in one study of ED patients older than 65 years [12]. However, some recent studies have failed to show gender differences at ages above 75 years $[20,21]$. We also found that NTproBNP above a level in accordance with heart failure had a strong correlation to a cTnT level of $\geq 15 \mathrm{ng} / \mathrm{L}$, whereas the clinical diagnosis of heart failure had not. It is well known that a diagnosis of heart failure based on clinical findings is very uncertain and patients are often managed without a confirming echocardiogram in PHC [22]. Hence, there may have been some undiagnosed cases of heart failure in the study. Renal function was not correlated to increased hs-cTnT according to the multivariate analyses, probably explained by the well-known influence of age on renal function.

A dynamic course of the cTnT level is an important diagnostic criteria for AMI [5]. However, a single hscTnT value could serve as decision support when safely ruling out AMI in patients with recent onset of symptoms or to diagnose AMI or UA with diffuse symptoms 
Table 4 Follow-up of 21 patients assessed for chest pain with an initial hs-cTnT level of $\geq 15$ ng/L but no signs of AMI or UA

\begin{tabular}{|c|c|c|c|c|}
\hline & \multirow{2}{*}{$\begin{array}{l}\text { hs-cTnT } \geq 15 \mathrm{ng} / \mathrm{L} \text { without } \\
\text { AMI or UA } n=21\end{array}$} & \multicolumn{2}{|c|}{ hs-cTnT after 2-3 years } & \multirow[t]{2}{*}{$P$ value } \\
\hline & & $<15 \mathrm{ng} / \mathrm{L} n=7$ & $\geq 15 \mathrm{ng} / \mathrm{L} n=14$ & \\
\hline Age (years) & $81 \pm 9$ & $75 \pm 9$ & $83 \pm 7$ & 0.049 \\
\hline Male & $16(76)$ & $5(71)$ & $11(79)$ & 1.000 \\
\hline \multicolumn{5}{|l|}{ Risk factors } \\
\hline Current smokers & 0 & 0 & 0 & \\
\hline Diabetes & $6(29)$ & $2(29)$ & $4(29)$ & 1.000 \\
\hline Hypertension & $18(86)$ & $5(71)$ & $13(93)$ & 0.247 \\
\hline Hypercholesterolaemia & $7(33)$ & $3(43)$ & $4(29)$ & 0.638 \\
\hline \multicolumn{5}{|l|}{ Cardiovascular disease } \\
\hline Angina pectoris & $1(5)$ & $1(14)$ & 0 & 0.333 \\
\hline Previous AMI & $3(14)$ & $2(29)$ & $1(7)$ & 0.247 \\
\hline Heart failure & $3(14)$ & $1(14)$ & $2(14)$ & 1.000 \\
\hline Aortic valve disease & $3(14)$ & $1(14)$ & $2(14)$ & 1.000 \\
\hline \multicolumn{5}{|l|}{ ECG findings } \\
\hline Atrial fibrillation & $8(38)$ & $2(29)$ & $6(43)$ & 0.656 \\
\hline \multicolumn{5}{|l|}{ Laboratory findings } \\
\hline eGFR (mL/min) & $62 \pm 17$ & $74 \pm 11$ & $56 \pm 16$ & 0.017 \\
\hline NT-proBNP (ng/L) $)^{a}$ & $440 \pm 775$ & $150 \pm 338$ & $1,245 \pm 883$ & 0.017 \\
\hline Cholesterol (mmol/L) & $4.5 \pm 1.3$ & $4.4 \pm 1.7$ & $4.6 \pm 1.2$ & 0.754 \\
\hline \multicolumn{5}{|l|}{ Symptoms and findings } \\
\hline Angina pectoris or dyspnoea & $3(14)$ & $2(29)$ & $1(7)$ & 0.247 \\
\hline Length (cm) & $173 \pm 7$ & $173 \pm 10$ & $173 \pm 7$ & 0.847 \\
\hline Body weight (kg) & $85 \pm 13$ & $85 \pm 10$ & $84 \pm 15$ & 0.889 \\
\hline $\mathrm{BMI}\left(\mathrm{kg} / \mathrm{m}^{2}\right)$ & $28 \pm 4$ & $29 \pm 5$ & $28 \pm 4$ & 0.862 \\
\hline Waist circumference $(\mathrm{cm})$ & $106 \pm 11$ & $107 \pm 11$ & $106 \pm 11$ & 0.878 \\
\hline Systolic BP $(\mathrm{mm} \mathrm{Hg})^{\mathrm{a}}$ & $120 \pm 10$ & $120 \pm 2.5$ & $130 \pm 11$ & 0.176 \\
\hline Diastolic BP $(\mathrm{mm} \mathrm{Hg})^{\mathrm{a}}$ & $70 \pm 6$ & $70 \pm 7$ & $65 \pm 6$ & 0.658 \\
\hline
\end{tabular}

Patients are divided into groups according to hs-cTnT level 2-3 years after the initial assessment.

Values are presented as mean \pm SD or number (\%) as appropriate.

a Median \pm quartile deviation.

of longer duration. A limit of detection well below $15 \mathrm{ng} / \mathrm{L}$ and the cardiac specificity of cTnT is a prerequisite for ruling out AMI in patients with recent onset of symptoms [5]. However, this gain in sensitivity for AMI would be at the expense of a low or very low positive predictive value as shown in Table 2 . There is no ideal POCT for the diagnosis of AMI within $6 \mathrm{~h}$ of onset of symptoms [23]. However, no patient in our study had a history of less than $10 \mathrm{~h}$ until the blood sample was drawn. After an AMI, the hs-cTnT value may remain above the decision limit of $\geq 15 \mathrm{ng} / \mathrm{L}$ for 2 weeks [5]. Therefore, we included all patients with onset or aggravation of symptoms during the last 7 days in order to detect all possible cases of AMI or UA. In a previous study, we found that the use of POCT-cTnT with a detection limit of $30 \mathrm{ng} / \mathrm{L}$ in primary care may occasionally result in missed diagnoses of UA or AMI, but as shown in Table 2, hs-cTnT may be a diagnostic support to find patients even with UA [11].

Although there are several POCT instruments equipped with methods to detect troponin, they all have methodological problems. Most methods for measuring troponin lack the high sensitivity of most hospital laboratory methods and some have problems with interfering substances [23, 24]. However, attempts to develop more sensitive POCT troponin assays have been made $[25,26]$. The POCT-cTnT used in this study had a detection level of $30 \mathrm{ng} / \mathrm{L}$ according to the manufacturer's specifications. However, when hs-cTnT was measured in samples drawn at the same time, a considerable number of patients had hs-cTnT levels above $30 \mathrm{ng} / \mathrm{L}$, but failed to give positive results with the POCT-cTnT (Figure 1). This emphasizes 
the need for proper validation of POCT methods both in relation to the detection limit and clinical outcome.

\section{Follow-up of patients with hs-cTnT levels $>15 \mathrm{ng} / \mathrm{L}$ but without signs of AMI or UA}

After 2-3 years, two-thirds of the 21 patients still had a cTnT level $\geq 15 \mathrm{ng} / \mathrm{L}$. This can be compared with the fact that ED patients, at least 75 years old and without conditions that increase cTnT, have been shown to have cTnT levels above the 99th percentile in 43-48\% of cases $[20,21]$. In one-third of these cases, cTnT levels had normalized after almost 3 years. Subclinical myocardial infarctions may have been present but there were no signs of q-waves on the ECG at followup. At the follow-up, patients with mild heart failure could possibly have had increased cTnT values at some time due to temporary infections or other causes that normalize without treatment [5]. There were more patients with atrial fibrillation, although not statistically significant, in the group with cTnT $>15 \mathrm{ng} / \mathrm{L}$. This is in accordance with previous studies showing that atrial fibrillation is associated with increased baseline cardiac troponin values $[27,28]$. It is well known that normal aging affects renal function and the level of NT-proBNP [18, 29]. However, our study group was too small for a multivariate analysis aiming to adjust eGFR and NT-proBNP for age.

\section{Strengths and limitations}

A major strength of the study is the prospective design and rigorous follow-up of patients, even if sent home, to evaluate missed diagnoses. A limitation is the low number of cases of AMI and UA influencing the reliability of the sensitivity and specificity calculations. However, this reflects the situation in Swedish primary care, where patients with acute chest pain symptoms are directed to emergency care without passing the PHC centre. A larger study population would probably lead to a clearer association between the level of hs-cTnT, atrial fibrillation and eGFR.

\section{Potential clinical implications}

The 99th percentile used to set the limit for ruling out using the cTnT level is based on measurements in a relatively young healthy population 20-71 years of age (median 45 years) [14]. In accordance with the results in this study, several authors have suggested that a higher limit has to be considered for patients older than $65-70$ years $[12,20,21]$, which is in line with our findings.

Additional clinical information could be gained if NTproBNP is analysed at the same time as hs-cTnT. Both these cardiac markers can possibly serve as tools for managing patients with cardiac disease in primary care when making the decision on whether to refer emergently for hospital care or to monitor non-acute cardiac patients.

\section{Conclusions}

A reliable POCT hs-cTnT could become valuable in primary care if applied to patients younger than 65 years presenting with symptoms suggestive of AMI or UA. For patients older than 65-70 years a higher decision limit of cTnT than $\geq 15 \mathrm{ng} / \mathrm{L}$ should be considered. The POCTcTnT instrument Cobas h232 did not perform analytically as well as specified by the manufacturer, especially in the lower measuring range. This study emphasizes that before introducing new methods for cardiac markers in primary care, the method must be validated by independent researchers and clinical outcomes should be evaluated in a large enough, typical, primary care patient population.

\section{Abbreviations}

AMl: acute myocardial infarction; cTnT: cardiac troponin T; ECG: electrocardiogram; ED: emergency department; eGFR: estimated glomerular filtration rate; GP: general practitioner; hs-cTnT: high sensitivity cardiac troponin T; NTproBNP. $\mathrm{N}$-terminal pro-B-type natriuretic peptide; $\mathrm{PHC}$ : primary health care; $\mathrm{POCT}$ : point-of-care test; UA: unstable angina.

\section{Authors' contributions}

POA, JEK, EL and SN conceived the study, participated in its design and coordination and helped to draft the manuscript. KF performed the statistical analysis and helped to draft the manuscript. All authors read and approved the final manuscript.

\section{Author details}

${ }^{1}$ Primary Health Care and Department of Medical and Health Sciences, Linköping University, Linköping, Sweden. ${ }^{2}$ Department of Internal Medicine, County Council of Jönköping, Jönköping, Sweden. ${ }^{3}$ Department of Medical and Health Sciences, Linköping University, SE-581 83 Linköping, Sweden.

${ }^{4}$ Department of Clinical Chemistry and Department of Clinical and Experimental Medicine, Linköping University, Linköping, Sweden. ${ }^{5}$ Primary Health Care and Department of Medical and Health Sciences, Linköping University, Norrköping, Sweden.

\section{Acknowledgements}

The authors wish to thank colleagues and staff at the primary health care centres of Kolmården, Vikbolandet and Åby for their contribution to the study. The study was supported by grants from the County Council of Östergötland.

\section{Compliance with ethical guidelines}

\section{Competing interests}

The authors declare that they have no competing interests.

Received: 8 April 2015 Accepted: 18 May 2015

Published online: 03 June 2015

\section{References}

1. Verdon F, Burnand B, Herzig L, Junod M, Pecoud A, Favrat B (2007) Chest wall syndrome among primary care patients: a cohort study. BMC Fam Pract 8:51 
2. Nilsson S, Scheike M, Engblom D, Karlsson LG, Molstad S, Akerlind I et al (2003) Chest pain and ischaemic heart disease in primary care. Br J Gen Pract 53(490):378-382

3. Svavarsdottir AE, Jonasson MR, Gudmundsson GH, Fjeldsted K (1996) Chest pain in family practice. Diagnosis and long-term outcome in a community setting [published erratum appears in Can Fam Physician 1996 Sep; 42:1672]. Can Fam Physician 42:1122-1128

4. Bosner S, Becker A, Haasenritter J, Abu Hani M, Keller H, Sonnichsen AC et al (2009) Chest pain in primary care: epidemiology and pre-work-up probabilities. Eur J Gen Pract 15(3):141-146

5. Thygesen K, Alpert JS, Jaffe AS, Simoons ML, Chaitman BR, White HD (2012) Third universal definition of myocardial infarction. Circulation 126(16):2020-2035. doi:10.1161/CIR.0b013e31826e1058

6. Aldous S, Gent P, McGeoch G, Nicholson D (2012) The use of troponin in general practice. NZ Med J 125(1357):36-43

7. Law K, Elley R, Tietjens J, Mann S (2006) Troponin testing for chest pain in primary healthcare: a survey of its use by general practitioners in New Zealand. NZ Med J 119(1238):U2082

8. Mann S, Tietjens J, Law K, Elley R (2006) Troponin testing for chest pain in primary healthcare: a New Zealand audit. NZ Med J 119(1238):U2083

9. Planer D, Leibowitz D, Paltiel O, Boukhobza R, Lotan C, Weiss TA (2006) The diagnostic value of troponin T testing in the community setting. Int J Cardiol 107(3):369-375. doi:10.1016/j.ijcard.2005.03.054

10. Tomonaga Y, Gutzwiller F, Luscher TF, Riesen WF, Hug M, Diemand A et al (2011) Diagnostic accuracy of point-of-care testing for acute coronary syndromes, heart failure and thromboembolic events in primary care: a cluster-randomised controlled trial. BMC Fam Pract 12:12. doi:10.1186/1471-2296-12-12

11. Nilsson S, Andersson PO, Borgquist L, Grodzinsky E, Janzon M, Point-ofCare Kvick M, Troponin T et al (2013) Point-of-Care troponin T testing in the management of patients with chest pain in the Swedish Primary Care. Int J Family Med. doi:10.1155/2013/532093

12. Hammarsten O, Fu M, Sigurjonsdottir R, Petzold M, Said L, Landin-Wilhelmsen K et al (2012) Troponin T percentiles from a random population sample, emergency room patients and patients with myocardial infarction. Clin Chem 58(3):628-637

13. Knebel F, Spethmann S, Schattke S, Dreger H, Schroeckh S, Schimke I et al (2012) Exercise-induced changes of left ventricular diastolic function in postmenopausal amateur marathon runners: assessment by echocardiography and cardiac biomarkers. Eur J Prev Cardiol. doi:10.1177/2047487312462799

14. Saenger AK, Beyrau R, Braun S, Cooray R, Dolci A, Freidank H et al (2011) Multicenter analytical evaluation of a high-sensitivity troponin T assay. Clin Chim Acta 412(9-10):748-754. doi:10.1016/j.cca.2010.12.034

15. Apple FS, Jaffe AS (2012) Clinical implications of a recent adjustment to the high-sensitivity cardiac troponin T assay: user beware. Clin Chem 58(11):1599-1600. doi:10.1373/clinchem.2012.194985
16. Levey AS, Coresh J, Greene T, Stevens LA, Zhang YL, Hendriksen S et al (2006) Using standardized serum creatinine values in the modification of diet in renal disease study equation for estimating glomerular filtration rate. Ann Intern Med 145(4):247-254

17. Rustad P, Felding P, Franzson L, Kairisto V, Lahti A, Martensson A et al (2004) The Nordic reference interval project 2000: recommended reference intervals for 25 common biochemical properties. Scand J Clin Lab Invest 64(4):271-284

18. Maisel A, Mueller C, Adams K, Anker SD, Aspromonte N, Cleland JG et al (2008) State of the art: using natriuretic peptide levels in clinical practice. Eur J Heart Fail 10(9):824-839

19. Eggers KM, Venge $P$, Lindahl B (2012) High-sensitive cardiac troponin $T$ outperforms novel diagnostic biomarkers in patients with acute chest pain. Clin Chim Acta 413(13-14):1135-1140

20. Mansour M, Clark L, Scott T, Worster A, Kavsak PA (2013) Considerations for establishing a reference interval for elderly individuals in the emergency department with the high-sensitivity cardiac troponin T assay. Clin Chim Acta 421:85-86

21. Menacer S, Claessens YE, Meune C, Elfassi Y, Wakim C, Gauthier L et al (2013) Reference range values of troponin measured by sensitive assays in elderly patients without any cardiac signs/symptoms. Clin Chim Acta 417:45-47

22. Agvall B, Borgquist L, Foldevi M, Dahlstrom U (2005) Cost of heart failure in Swedish primary healthcare. Scand J Prim Health Care 23(4):227-232

23. Bruins Slot MH, van der Heijden GJ, Stelpstra SD, Hoes AW, Rutten FH (2013) Point-of-care tests in suspected acute myocardial infarction: a systematic review. Int J Cardiol 168(6):5355-5362

24. Palamalai V, Murakami MM, Apple FS (2013) Diagnostic performance of four point of care cardiac troponin I assays to rule in and rule out acute myocardial infarction. Clin Biochem 46(16-17):1631-1635

25. Lee W, Jung J, Hahn YK, Kim SK, Lee Y, Lee J et al (2013) A centrifugally actuated point-of-care testing system for the surface acoustic wave immunosensing of cardiac troponin I. Analyst 138(9):2558-2566

26. Zhang J, Kruss S, Hilmer AJ, Shimizu S, Schmois Z, De La Cruz F et al (2013) A rapid, direct, quantitative, and label-free detector of cardiac biomarker troponin T using near-infrared fluorescent single-walled carbon nanotube sensors. Adv Healthc Mater 21(10):201300033. doi:10.1002/ adhm.201300033

27. Parwani AS, Boldt LH, Huemer M, Wutzler A, Blaschke D, Rolf S et al (2013) Atrial fibrillation-induced cardiac troponin I release. Int J Cardiol 168(3):2734-2737

28. Anegawa T, Kai H, Adachi H, Hirai Y, Enomoto M, Fukami A et al (2012) High-sensitive troponin $\mathrm{T}$ is associated with atrial fibrillation in a general population. Int J Cardiol 156(1):98-100. doi:10.1016/j.ijcard.2011.12.117

29. Maw T, Fried L (2013) Chronic kidney disease in the elderly. Clin Geriatr Med 29(3):611-624

\section{Submit your next manuscript to BioMed Central and take full advantage of:}

- Convenient online submission

- Thorough peer review

- No space constraints or color figure charges

- Immediate publication on acceptance

- Inclusion in PubMed, CAS, Scopus and Google Scholar

- Research which is freely available for redistribution

Submit your manuscript at

www.biomedcentral.com/submit

C Biomed Central 